\title{
Wound healing activity of an herbal ointment containing the leaf extract of Ziziphus Mauritiana Lam.
}

\author{
D. Senthil Rajan ${ }^{1 \star}$, M. Rajkumar ${ }^{2}$, C. T. Kumarappan ${ }^{1}$ and K. L. Senthil Kumar ${ }^{2}$ \\ ${ }^{1}$ School of Pharmacy, International Medical University, Bukit Jalil, Kuala Lumpur, Malaysia. \\ ${ }^{2}$ Department of Pharmacognosy, Padmavathi College of Pharmacy and Research Institute, India.
}

Accepted 19 November, 2012

\begin{abstract}
A large number of plants are used by folklore traditions in India for treatment of cuts, wounds and burns. Particularly, the leaves of Ziziphus mauritiana Lam. (Family: Rhamnaceae) have been practiced on wounds for healing. The aim of the present investigation was to assess the in vivo wound healing efficacy of prepared topical formulation of $5 \% \mathrm{w} / \mathrm{w}$ ethanolic extract ointment and $5 \% \mathrm{w} / \mathrm{w}$ of aqueous extract ointment and nitrofurazone ointment $(0.2 \% \mathrm{w} / \mathrm{w})$ on excision wound model in Wistar albino rats. The effect produced by ointment, in terms of wound contracting ability, wound closure, decrease in surface area of wound, tissue regeneration at the wound site in treated Wistar albino rats shows that proliferation of epithelial tissue promotes angiogenesis, multiplication of fibrous connective tissue due to treatment with $Z$. mauritiana. Acute toxicity studies revealed the non-toxic nature of $Z$. mauritiana. Ethanolic extract ointment $(5 \% \mathrm{w} / \mathrm{w})$ of $Z$. mauritiana manifested $99 \%$ wound contraction on the 16 th day. These results were also comparable to those of a standard drug, nitrofurazone. Topical formulation with $5 \% \mathrm{w} / \mathrm{w}$ ethanolic extract promoted wound contraction and reduced the wound closure time, so increase in tensile strength and wound contraction shows the wound healing potential of $Z$. mauritiana. Thus, the present study supports the scientific rationale for the traditional use of this plant in the management of wounds.
\end{abstract}

Key words: Herbal ointment, Ziziphus mauritiana, wound healing, wistar albino rats.

\section{INTRODUCTION}

Wound infection is one of the most common diseases in developing countries because of poor hygienic conditions (Senthil Kumar et al., 2006). Healing of wounds starts from the moment of injury and can continue for varying periods of time, depending on the extent of wound, and the process can be broadly categorized into three stages; inflammatory phase, proliferation phase, and finally the remodeling phase which ultimately controls the strength and appearance of the healed tissue (Sumitra et al., 2005). Wound healing process occurs in several steps which involve coagulation, inflammation, formation of granulation tissue, matrix formation, remodeling of con-

${ }^{*}$ Corresponding author. E-mail: senthil_rajan@imu.edu.my. Tel: +60327317310. nective tissue, collagenization and acquisition of wound strength (Suresh et al., 2002). Research on wound healing agents is one of the developing areas in modern biomedical sciences and many traditional practitioners across the world, particularly in countries like India and China have valuable information of many lesser known hitherto unknown wild plants for treating wounds and burns (Kumar et al., 2007). Many medicinal plants are claimed to be useful for wound healing in the traditional system of medicine. These plant remedies (both single plant and multiherbal reparations) are used since ancient times even though the mechanism of action and efficacy of only very few of them have been evaluated scientifically (Nagappa et al., 2001). Z. mauritiana Lam. (Family: Rhamnaceae) is commonly known as jujube tree or Indian jujube, magarya in Hause and whuya in Kilba 
(Nigeria). The leaves of the plant are used in the treatment of diarrhoea, wounds, abscesses, swelling, gonorrhea, liver diseases, asthma and fever (Morton, 1987; Michel, 2002). The different parts of the plant are used as cuts and ulcers healer, pulmonary ailments, fevers, laxative, sedative, anti-nausea, anti-rheumatic areas, anti-diarrhoeal, wounds and abscesses healer, swelling, gonorrhoea curer (Michel, 2002), and also used as anthelmintic in ethnoveterinary medicinal system in Pakistan (Hussain et al., 2008). They are also used to treat pulmonary ailments, dysentery, fevers and skin diseases (Adzu et al., 2001). The antioxidant activity of the aqueous extract of $Z$. mauritiana leaf has been reported (Dahiru and Obidoa, 2008). The hepatoprotective activity of ethanol extract of $Z$. mauritiana leaf against $\mathrm{CCl}_{4}$-induced liver damage in rats and the antidiarrhoea activity of the methanol root extract have also been reported (Dahiru et al., 2006).

In the present study, an indigenous herbal extract of $Z$. mauritiana which is being claimed to have the potential in the treatment of wounds was selected for the evaluation of wound healing activity of aqueous and ethanolic extract in excision wound models in wistar albino rats.

\section{MATERIALS AND METHODS}

\section{Collection of plant material}

The leaves of $Z$. mauritiana were collected from the Botanical garden at the Campus of Padmavathi College of Pharmacy, Dharmapuri. The plant was identified and authenticated by Dr. P. Jayaraman, Botanist, Director of Plant Anatomy Research Centre (PARC), Chennai, India. A voucher specimen (PARC/2009/385) was deposited at the herbarium for future reference. The leaves were powdered by means of a wood-grinder and the powder was passed through the sieve no.60 for powder analysis and the coarse fraction was subjected to phytochemical studies.

\section{Preparation of aqueous extract}

Crude aqueous extract (CAE) of powdered Z. mauritiana was prepared according to the standard methods (Fenado et al., 1989). Briefly, $100 \mathrm{~g}$ of the powdered leaves were mixed with $500 \mathrm{~mL}$ of distilled water in a $1 \mathrm{~L}$ flask and boiled for $1.5 \mathrm{~h}$. Extract was filtered using Whatman No.1 filter paper after cooling it to $40^{\circ} \mathrm{C}$. The filtrate was concentrated in a rotary evaporator under vacuum $\left(40^{\circ} \mathrm{C}\right)$ and the concentrated extract was stored at $4^{\circ} \mathrm{C}$ until use. The yield was found to be aqueous extract $8.16 \% \mathrm{w} / \mathrm{w}$.

\section{Preparation of ethanolic extract}

Crude ethanolic extract of powered plants was prepared according to the standard methods (Gilani et al., 2004). Briefly, $1 \mathrm{~kg}$ of ground plant material was soaked in sufficient quantity of $70 \%$ aqueousethanol by cold maceration at room temperature for three days after which the filtrate was collected through a piece of muslin cloth and then filter paper and the plant material was resoaked twice. The filtrate was concentrated in a rotary evaporator at $40^{\circ} \mathrm{C}$ under reduced pressure to yield crude extract. This extract was stored at $4^{\circ} \mathrm{C}$ until use. The yield was found to be ethanolic extract $8.4 \%$ $\mathrm{w} / \mathrm{w}$.

\section{Formulation of the Herbal ointment}

After preparation of extract and phytochemical studies, the next step was to formulate a polyherbal preparation. A simple ointment base as per Indian pharmacopeia was prepared by fusion method. It was of first choice due to their ease of preparation, rapid absorption into the skin and also eases of cleaning after application. The weighed quantities of the extract was weighed, added to the molten ointment base and then homogenized in tile by trituration. Four batches of the simple ointment (Group I to III) were prepared and used in the study. Group I received no drug or extract (control). Group II received 5\% ethanolic extract of the ointment base. Group III received 5\% aqueous extract of the ointment base. Group IV received nitrofurazone ointment $(0.2 \% \mathrm{w} / \mathrm{w})$ (Standard).

\section{Animals used}

Wistar male albino rats (150 to $180 \mathrm{~g}$ ) were selected for evaluation of wound healing activity. Six rats were taken for each group. The rats were used after acclimatization under controlled conditions of temperature of $23 \pm 2^{\circ} \mathrm{C}$, humidity of $50 \pm 5 \%$ and 10 to $14 \mathrm{~h}$ of light and dark cycles, respectively for 7 days. The animals were housed individually in polypropylene cages containing sterile paddy husk (procured locally) as bedding throughout the experiment and had free access to sterile food (animal chow) and water ad libitum. The animal experimental study was conducted after obtaining the approval of Institutional Animal Ethics Committee, Padmavathi College of Pharmacy. Animal experiments were performed in accordance with the principles of good laboratory practices and Committee for the Purpose of Control and Supervision of Experiments on Animals (CPCSEA) guidelines of the Government of India.

\section{Study design}

The animals were randomly allocated into four groups of six animals each for the Excision wound experimental model. Group I received $0.5 \mathrm{~g}$ of Simple ointment (Control); Group II received 5\% ethanolic extract in simple ointment (w/w); Group III received 5\% aqueous extract in simple Ointment (w/w); Group IV received nitrofurazone ointment $(0.2 \% \mathrm{w} / \mathrm{w})$ (Standard).

\section{Excision wound model}

An excision wound model was used for studying wound healing activity in male albino rats as described by Nagappa et al. (2001), with some modification. Animals were anesthetized prior to and during creation of the wounds with $1 \mathrm{ml}$ of intravenous ketamine hydrochloride (10 $\mathrm{mg} / \mathrm{kg}$ body wt). Hair was removed by shaving the nape of the back of all the rats. Ethanol (70\%) was used as antiseptic for the shaved region before making the wound. A full thickness of the excision wound of uniform $2.5 \mathrm{~cm}$ diameter circular area was created along the markings using toothed forceps, scalpel and pointed scissors. The wound was left undressed to the open environment and no local or systemic anti-microbial agents were used. The rats were distributed in groups randomly and each rat was placed in an individual cage. The wistar albino rats were divided into different groups and the test samples (Z. mauritiana extracts) were formulated as an ointment in simple ointment base. $0.5 \mathrm{~g}$ of the formulated ointment was applied on the wound once daily for 16 days starting from the day of wounding. The observation of percentage wound closure were made on 2nd, 4th, 8 th and 16th day post wounding days. Wound area was measured by retracing the wound on a millimeter scale graph paper. 
Table 1. Qualitative preliminary phytochemical screening of ethanolic and aqueous extracts of powdered leaves of Ziziphus mauritiana, Lam.

\begin{tabular}{llll}
\hline S/No & Phytoconstituents & $\begin{array}{l}\text { Ethanolic } \\
\text { extract }\end{array}$ & $\begin{array}{l}\text { Aqueous } \\
\text { extract }\end{array}$ \\
\hline 1 & Alkaloids & + & + \\
2 & Saponins & $(-)$ & + \\
3 & Glycosides & $(-)$ & $(-)$ \\
4 & Carbohydrates & + & + \\
5 & Tannins and Phenolic compounds & + & + \\
6 & Fixed oils and fats & $(-)$ & $(-)$ \\
7 & Flavonoids & + & + \\
8 & Phytosterols & $(-)$ & + \\
9 & Proteins and amino acids & + & + \\
10 & Terpenoids & + & $(-)$ \\
11 & Gums and Mucilages & $(-)$ & $(-)$ \\
12 & Lignin & $(-)$ & + \\
\hline
\end{tabular}

$(+)=$ Present $(-)=$ Absent .

\section{Statistical data analysis}

Results were expressed as mean \pm standard error of mean (SEM). Statistical comparison were made by using one-way Analysis of variance (ANOVA), followed by Student and Dunnet multiple ' $t$ ' comparison test using Graph Pad Prism software (GraphPad software Inc., Version 4.0.0.255) and difference were considered statistically significant when $\mathrm{P}$-values were $<0.05$.

\section{RESULTS AND DISCUSSION}

Phytochemical investigation of ethanolic and aqueous extracts of the test plant showed the presence of alkaloids, flavonoid, phenolic compounds and tannins in Z. mauritiana Lam. Also, no sample showed the presence of glycosides. The details of qualitative chemical tests and phytoconstituents present in the extracts are shown in Table 1. The mean wound contraction in the control group was $53.50 \%$ (from $506.5 \pm 4.61$ to $235.5 \pm 4.1 \%$ ) on 16th day. The measurements of the progress of the wound contraction induced by the simple ointment (control), ethanolic extract in simple ointment $(5.0 \% \mathrm{w} / \mathrm{w})$, aqueous extract in simple Ointment $(5 \% \mathrm{w} / \mathrm{w})$, the nitro furazone ointment $(0.2 \% \mathrm{w} / \mathrm{w})$ (Standard) are shown in the Table 2. It is observed that the wound contracting ability of the ethanolic extract in simple ointment $(5 \%$ $\mathrm{w} / \mathrm{w})$ is significantly greater than that of the aqueous extract in simple ointment $(5 \% \mathrm{w} / \mathrm{w})$. No death was observed for any of the rats in the study groups and there were no remarkable changes in animal behavior or general appearance.

In the present study, the wound healing potential in albino rats for of $Z$. Mauritiana Lam. was evident on the day 16. No healing effect was observed with simple ointment (control) in albino rats (Table 2). On days 2, 4,
8, 12 and 16, animals treated with the ethanolic extract in simple ointment $(5 \% \mathrm{w} / \mathrm{w})$ showed results similar to animals treated with nitrofurazone ointment $(0.2 \% \mathrm{w} / \mathrm{w}$, (Standard), with improving the wound healing process (Table 2, Figures 2 and 3). It is observed that the wound contraction ability of the test formulation was significantly greater than that of the control and reference standard $(p$ $<0.05$ ) (Table 2, Figures 1, 2 and 3).

Granulation, collagen maturation and scar formation are some of the many phases of wound healing which run concurrently, but independent of each other. The process of wound healing occurs in four phases (i) coagulation, which prevents blood loss; (ii) inflammation and debridement of wound; (iii) repair, including cellular proliferation and; (iv) tissue remodeling and collagen deposition. Any phytochemical which accelerates the above process is a promoter of wound healing. Plant products have been shown to possess good therapeutic potential as anti- inflammatory agents and promoter of wound healing due to the presence of active terpenes, alkaloids and flavonoids (Dahiru et al., 2005; Shafaghat et al., 2010). The wound healing property of $Z$. Mauritiana Lam. appears to be due to the presence of its active principles which accelerates the healing process and confers breaking strength to the healed wound. Wound contraction is the process of mobilizing healthy skin surrounding the wound to cover the denuded area. This centripetal movement of wound margin is believed to be due to the activity of myofibroblast (Gabbaiani et al., 1976). Since Z. Mauritiana extract enhanced wound contraction, it would have either enhanced contractile property of myofibroblasts or increased the number of myofibroblasts recruited into the wound area.

The results in this study are in support that the wound healing and repair is accelerated by applying $Z$. 
Table 2. Effect of topically applied Ziziphus Mauritiana Lam leaves extracts on excision wound model in rats.

\begin{tabular}{|c|c|c|c|c|c|c|}
\hline \multirow{2}{*}{ Animal treatment groups ${ }^{\star}$} & \multicolumn{6}{|c|}{ Wound contraction $\left(\mathrm{mm}^{2}\right)$ on day \pm SE and percentage of wound contraction } \\
\hline & 0 day & 2nd day & 4th day & 8th day & 12th day & 16th day \\
\hline Group 1: Simple ointment (control) & $506.5 \pm 4.61(0.0)$ & $455.4 \pm 5.71(10.0)$ & $402.3 \pm 7.1(20.5)$ & $325.6 \pm 3.3(35.71)$ & $281.2 \pm 3.3(44.50)$ & $235.5 \pm 4.1(53.50)$ \\
\hline $\begin{array}{l}\text { Group 2: } 5 \% \text { w/w Ethanolic extract in } \\
\text { simple ointment }\end{array}$ & $512.6 \pm 3.5(0.0)$ & $410.5 \pm 5.6(19.9)$ & $325.4 \pm 6.1(36.51)$ & $140.8 \pm 4.3(72.53)$ & $32.5^{\star \star} \pm 1.5(93.65)$ & $5.1^{\star \star} \pm 0.3(99.0)$ \\
\hline $\begin{array}{l}\text { Group 3: } 5 \% \text { w/w Aqueous extract in } \\
\text { simple Ointment }\end{array}$ & $507.4 \pm 4.7(0.0)$ & $439.7 \pm 7.5(13.34)$ & $368.9 \pm 5.6(27.29)$ & $180.6 \pm 4.2(64.4)$ & $62.4^{*} \pm 3.8(87.7)$ & $25.8^{* *} \pm 1.1(94.9)$ \\
\hline $\begin{array}{l}\text { Group 4: Nitro furazone ointment } \\
(0.2 \% \mathrm{w} / \mathrm{w}) \text { (Standard) }\end{array}$ & $510.5 \pm 5.1(0.0)$ & $397.6 \pm 5.9(22.1)$ & $308.3 \pm 5.0(22.1)$ & $123.2 \pm 3.4(75.8)$ & $21.1^{\star \star} \pm 1.4(95.8)$ & $0.00^{* * *}(100)$ \\
\hline
\end{tabular}

Values are mean \pm SEM $(n=6)$ statically significant difference in comparison with control group: $P<0.05$. *Once a day, for 16 day; control, no treatment.
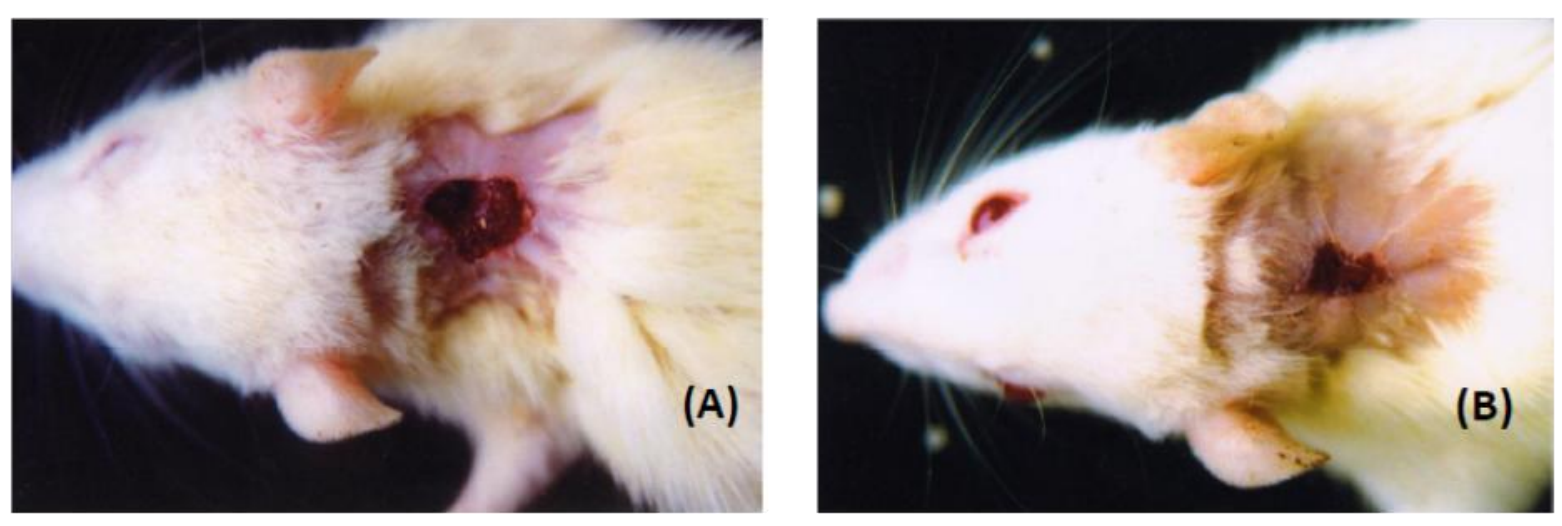

Figure 1. Excision wound healing effect of aqueous extract $(5 \% \mathrm{w} / \mathrm{w})$ in simple ointment treated rat on 8 th $(A)$ and 16 (B) days observation.

Mauritiana Lam., which was highlighted by the full thickness coverage of the wound area by an organized epidermis in the presence of mature scar tissue in the dermis (Table 2, Figures 1 and 3 ). The enhanced capacity of wound healing with
Z. Mauritiana Lam. could be explained on the basis of the anti-inflammatory effects of the plants that are well documented in the literature (Radhika et al., 2012).On the basis of the results obtained in the present investigation, it is possible to conclude that the ointment of the ethanolic extract of $Z$. Mauritiana Lam. has significant wound healing activity (Table 2 and Figure 2). The antioxidant and anti-inflammatory activities of flavonoids in ethanolic extract and aqueous 

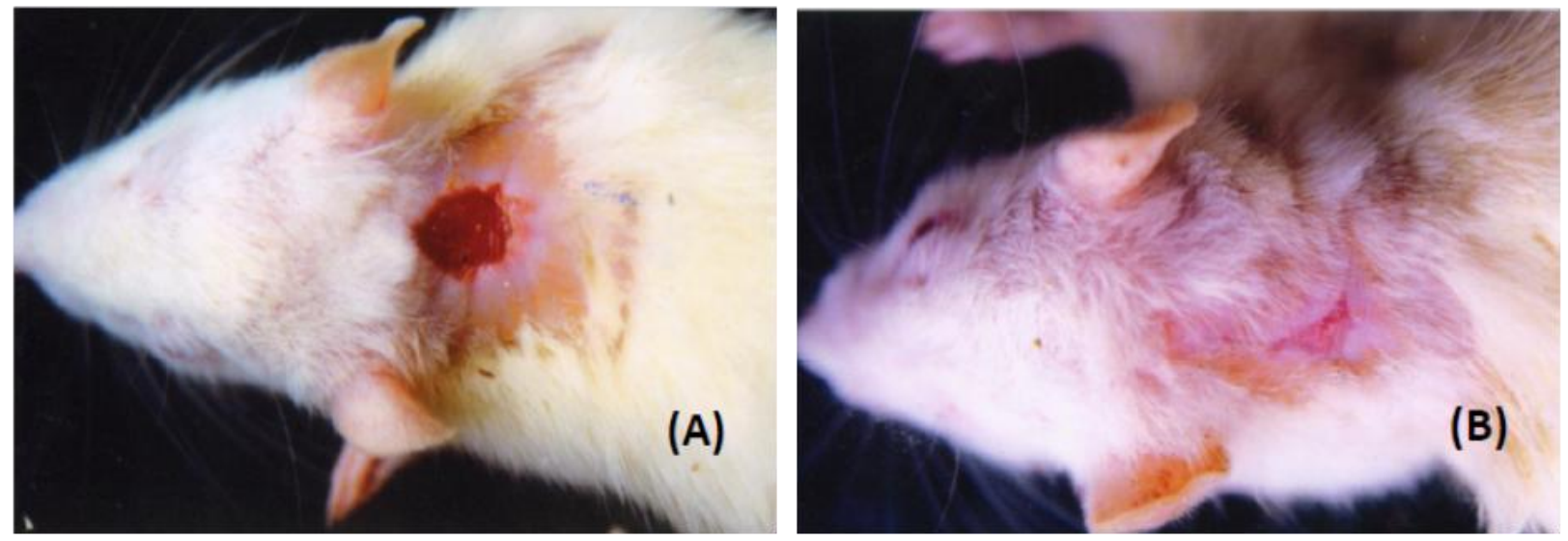

Figure 2. Excision wound healing effect of ethanolic extract $(5 \% \mathrm{w} / \mathrm{w})$ in simple ointment treated rat on 8 th $(A)$ and $16(B)$ days observation.
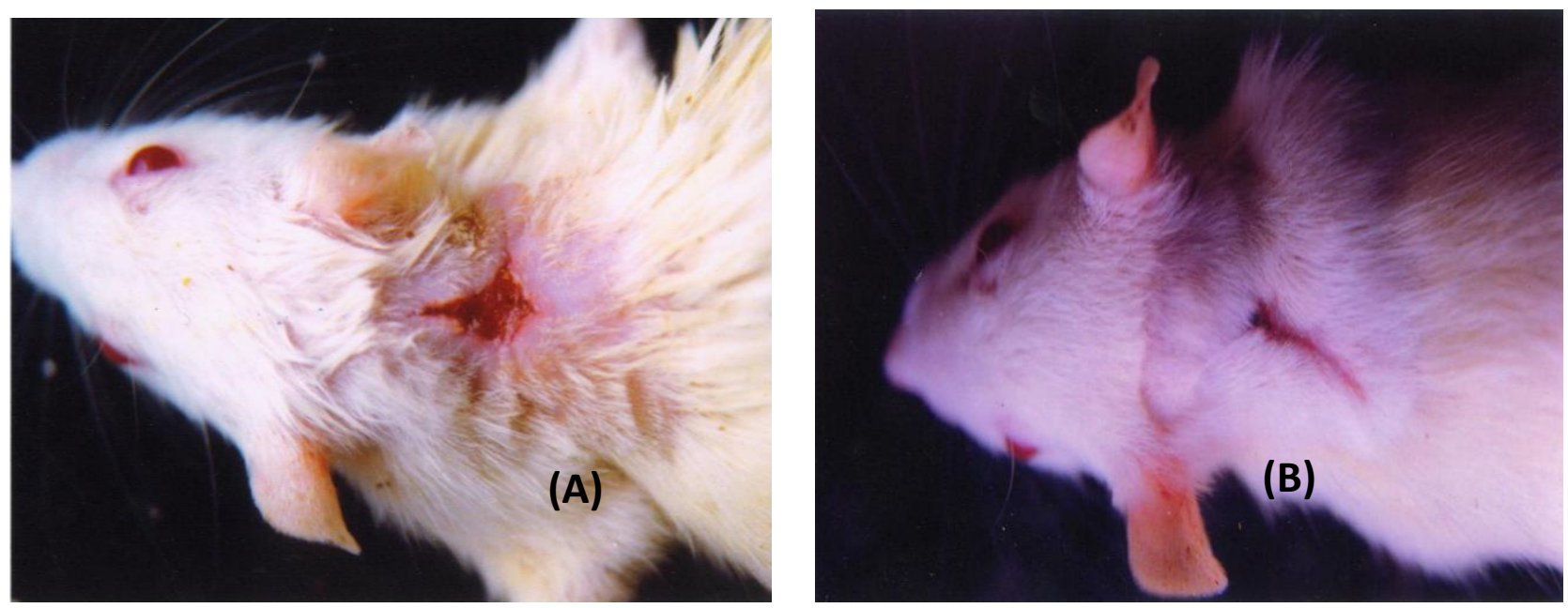

Figure 3. Excision wound healing effect of Nitrofurazone ointment $(0.2 \% \mathrm{w} / \mathrm{w})$ treated rat on 8 th $(A)$ and $16(B)$ days observation.

extract were believed to be one of the important mechanisms in wound healing (Marwah et al., 2007), and in the presence of tannin it improved the regeneration and organization of the new tissue and hastened the wound healing process (Leite et al., 2002).

Several phytoconstituents like alkaloids and saponins are known to promote wound healing process due to their antioxidant and antimicrobial activities. The active principal agent responsible for the wound healing activity of leaves of $Z$. mauritiana and their mechanisms of action have not so far been elucidated. However, phytochemical screening of the plant extract revealed the probable presence of tannins and flavonoids which are reported to have good wound healing property (Shafaghat et al., 2010; Mughal et al., 2011; Kamal et al., 2009). The results of wound contraction studies indicate that both the formulations enhance wound healing in open wounds due to antioxidant and anti-inflammatory properties.

\section{Conclusion}

In this study, topical application of the ethanolic extract of Z. Mauritiana Lam. incorporated into an ointment base on the excision wound in rats caused a significantly $(\mathrm{P}<$ 0.05 ) higher rate of wound healing and reduced the epithelialization period. The study reveals that both ethanolic extract and aqueous extract of $Z$. Mauritiana Lam. possesses good wound healing properties which may be attributed to the individual or combined action of phytoconstituents like alkaloids, and terpenoids present in the extract. Further investigations are necessary to determine the bioactive constituents present in the extracts to prove its potential in clinical studies.

\section{REFERENCES}

Adzu B, Amos S, Wambebe C, Gamaniel K (2001). Antinociceptive 
activity of Ziziphus spinachristi root bark extract. Fitoterapia. 72: 334350.

Dahiru D, Sini JM, John-Africa L (2006). Antidiarrhoeal activity of Ziziphus mauritiana root extract in rodents. Afr. J. Biotechnol. 5(10): 941-945.

Dahiru D, Obidoa O (2008). Evaluation of the antioxidant effects of Ziziphus mauritiana lam. Leaf extracts against chronic ethanolinduced hepatotoxicity in rat liver. Afr. J. Trad. CAM. 5(1): 39 45.

Fenado MR, Wickramasinghe SMD, Thabre MI, Karunayaka EH (1989). A preliminary investigation of the possible hypoglycaemic activity of Asteracanthus longifolia. J.Ethno. Pharmacol. 27: 7-14

Gabbaiani G, Harschel BJ, Ryan GB.(1976). Granulation tissue as a contractile organ. J. Exp Med. 135: 719.

Gilani AH, Ghayur MN, Saify ZS, Ahmad SP, Choudary MI, Khalid A (2004). Presence of cholinomimetic and acetylcholinesterase inhibitory constituents in betel nut. Life Science. 75: 2377-2389.

Hussain A , Khan MN, lqbal Z, Sajid MS (2008). An account of the botanical anthelmintics used in traditional veterinary practices in Sahiwal district of Punjab, Pakistan. J. Ethnopharmacol. 119: 185190.

Kamal M, Wazir SM, Hassan M, Subhan M, Khan SU, Muhammad M, Taj S ( 2009). Ethnobotanically important plants of District Bannu, Pakistan. Pak. J. Plant Sci. 15: 87-93.

Kumar B, Vijayakumar M, Govindarajan R, Pushpangadan P (2007). Ethno pharmacological approaches to wound healing-Exploring medicinal plants of India. J. Ethnopharmacol. 114: 103-113.

Leite SN, Palhano G, Almeida S, Biavattii MW (2002). Wound healing activity and systemic effects of Vernonia scorpioides gel in guinea pig. Fitoterapia.73: 496-500.

Marwah RG, Fatope MO, Mahrooqi RA, Varma GB, Abai HA, AlBurtamani SAS (2007). Antioxidant capacity of some edible and wound healing plants in Oman. Food Chem. 101: 465-470.
Michel A (2002). Tree, Shrub and Liana of West African Zones. Margraf Publishers GMBH, Paris. p. 440.

Morton J (1987). Indian Jujube. In: J. F. Morton (Eds.). Fruits of warm climates, Miami, Florida. pp. 272-275.

Nagappa AN, Cheriyan Binu (2001). Wound healing activity of the aqueous extract of Thespesia populnea fruit. Fitotherapia. 72: 503 506.

Radhika J, Jothi G, Revathy A, Sathya P, Sathya K (2012). Wound Healing Potentials of Ziziphus Mauritiana Lam (Bark) In Excision Wounds In Albino Rats. Int. J. Nat Prod. Sci. 2(1): 1-8.

Senthil Kumar M, Sripriya R, Vijaya Raghavan H, Sehgal P (2006). Wound Healing Potential of Cassia fistula on Infected Albino Rat Model. J. Surg. Res. 131: 283-289.

Sumitra M, Manikandana P, Suguna L (2005). Efficacy of Butea monosperma on dermal wound healing in rats. Int $\mathrm{J}$ Biochem Cell Biol. 37: 566-573.

Suresh Reddy J, Rao PR, Reddy MS (2002). Wound healing effects of Heliotropium indicum, Plumbago zeylanicum and Acalypha indica in rats. J. Ethnopharmacol. 79: 249-251.

Shafaghat A, Salimi F, Aslaniyan N, Shoaei Z (2010). Flavonoids and an ester derivative isolated from Galium verum $\mathrm{L}$. World Appl. Sci. J. 11(4):473-477. 